\title{
Recent Trend in Therapeutic Hypothermia and Early-Onset Pneumonia in Cardiac Arrest
}

\author{
Deokkyu Kim, M.D. \\ Department of Anesthesiology and Pain Medicine, Chonbuk National University Hospital, Jeonju, Korea
}

The ultimate goal of cardiopulmonary resuscitation (CPR) is restoring spontaneous circulation and minimizing neurologic deficits. Since two human studies presented improved neurologic outcome and reduced mortality after cardiac arrest in 2002,[1,2] therapeutic hypothermia $(\mathrm{TH})$ has been recommended consistently in the international CPR guidelines for post-cardiac arrest care.[3-5] TH improves the neurologic outcome due to attenuation of the inflammatory response in the brain.[1] On the other hand, TH can have systemic adverse effect such as high infection rate. Geurts et al.[6] emphasized in a meta-analysis of 23 studies that TH was a risk factor of both pneumonia and sepsis after return of spontaneous circulation in cardiac arrest patients.

Even if $\mathrm{TH}$ is not used, infection is more common in post-cardiac arrest care,[7] and pneumonia is the most common type of infection in out-of-hospital cardiac arrest (OHCA).[8] The cause of this high incidence of pneumonia in OHCA is that factors such as loss of airway protection, changed mental status, pulmonary contusion by chest compression, emergent airway access, and mechanical ventilation increase the risk of pulmonary infection.[7] Some studies have suggested that post-resuscitation pneumonia could be divided into early-onset and late-onset pneumonia according to onset time and prevalent pathogens; however, the onset time varied from three to seven days depending on the study.[8-11] Perbet et al.[11] reported that TH was an independent risk factor of early-onset pneumonia (EOP), which prolonged mechanical ventilation support and intensive care unit (ICU) stay with unchanged neurologic outcome and ICU mortality in a retrospective and large (641 patients) cohort study. Therefore, intensivists should be aware of management of EOP while conducting HT.

Prophylactic antibiotics decreased the incidence of EOP in comatose patients with a variety of causes such as head trauma, intracranial hemorrhage, stroke, or cardiac arrest.[12] In a recently published study, prophylactic antibiotics reduced the incidence of pneumonia in cardiac arrest survivors undergoing $\mathrm{TH}$, but they did not reduce patient mortality.[13] However, the researchers did not distinguish early- or late-onset pneumonia. Kim et al.[14] have reported that prophylactic antibiotics in OHCA patients undergoing TH does not reduce the incidence of EOP. The authors insisted that the study evaluated the effect of prophylactic antibiotics on EOP for the first time. The incidence of EOP was $29.2 \%$ and $30.0 \%$ in prophylactic antibiotics and non-antibiotics, respec-

\author{
Deokkyu Kim \\ Department of Anesthesiology and Pain \\ Medicine, Chonbuk National University \\ Hospital, Geonij-ro 20, Deokin-gu, \\ Jeonju 54907, Korea \\ Tel: +82-63-250-1527 \\ Fax: $+82-63-250-1240$ \\ E-mail: aneduke@jbnu.ac.kr \\ ORCID \\ Deokkyu Kim \\ http://orcid.org/0000-0001-7613-3529 \\ *No potential conflict of interest relevant to this \\ article was reported.
}


tively. Also, the study showed that prophylactic antibiotics did not have an effect on the duration of mechanical ventilation, the length of ICU stay, in-hospital mortality, or the cerebral performance category. This study suggested that the outcome in Korea may be different from those of Europe and North American countries in many aspects such as emergency health care condition, social support for trauma care, and medical expenses, etc. If the probability of EOP is overlooked in post-cardiac arrest care, serious infection can lead to high mortality. It is important to consider that patients who received TH are at high risk of EOP, and timely and appropriate antibiotic management is crucial. However, that study[14] was a single-center retrospective study with relatively small numbers, so the benefit of prophylactic antibiotics has not yet been adequately demonstrated. Welldesigned prospective studies are required in the future.

A TH range of $32^{\circ} \mathrm{C}$ to $34^{\circ} \mathrm{C}$ was strongly recommended for patients with OHCA in the 2010 international CPR guideline.[4] However, the recommended temperature range has been extended from $32^{\circ} \mathrm{C}$ to $36^{\circ} \mathrm{C}$ in the 2015 guideline. [5] This guideline specified that the temperature should be maintained at a constant level. Also, specific features should be considered when selecting the target temperature. If bleeding or infection is more likely in patients as a complication of the lower temperature environment, a relatively higher temperature should be recommended. Conversely, if a patient presents seizure or cerebral edema, a relatively lower temperature is preferred. The recommended duration of HT is at least 24 hours after achieving the target temperature. In addition, in patients with OHCA, routine prehospital cooling with rapid infusion of cold intravenous fluids is not recommended. In all coma cases, fever should be actively prevented.

\section{References}

1) Hypothermia after Cardiac Arrest Study Group: Mild therapeutic hypothermia to improve the neurologic outcome after cardiac arrest. N Engl J Med 2002; 346: 549-56.

2) Bernard SA, Gray TW, Buist MD, Jones BM, Silvester W, Gutteridge G, et al: Treatment of comatose survivors of out-of-hospital cardiac arrest with induced hypother- mia. N Engl J Med 2002; 346: 557-63.

3) Nolan JP, Morley PT, Vanden Hoek TL, Hickey RW, Kloeck WG, Billi J, et al: Therapeutic hypothermia after cardiac arrest: an advisory statement by the advanced life support task force of the International Liaison Committee on Resuscitation. Circulation 2003; 108: 118-21.

4) Deakin CD, Morrison LJ, Morley PT, Callaway CW, Kerber RE, Kronick SL, et al: Part 8: advanced life support: 2010 international consensus on cardiopulmonary resuscitation and emergency cardiovascular care science with treatment recommendations. Resuscitation 2010; 81 Suppl 1: e93-e174.

5) Callaway CW, Donnino MW, Fink EL, Geocadin RG, Golan E, Kern KB, et al: Part 8: post-cardiac arrest care: 2015 American Heart Association guidelines update for cardiopulmonary resuscitation and emergency cardiovascular care. Circulation 2015; 132(18 Suppl 2): S465-82.

6) Geurts M, Macleod MR, Kollmar R, Kremer PH, van der Worp HB: Therapeutic hypothermia and the risk of infection: a systematic review and meta-analysis. Crit Care Med 2014; 42: 231-42.

7) Adrie C, Adib-Conquy M, Laurent I, Monchi M, Vinsonneau C, Fitting C, et al: Successful cardiopulmonary resuscitation after cardiac arrest as a "sepsis-like" syndrome. Circulation 2002; 106: 562-8.

8) Tsai MS, Chiang WC, Lee CC, Hsieh CC, Ko PC, Hsu CY, et al: Infections in the survivors of out-of-hospital cardiac arrest in the first 7 days. Intensive Care Med 2005; 31: 621-6.

9) Mongardon N, Perbet S, Lemiale V, Dumas F, Poupet H, Charpentier J, et al: Infectious complications in out-ofhospital cardiac arrest patients in the therapeutic hypothermia era. Crit Care Med 2011; 39: 1359-64.

10) Rello J, Vallés J, Jubert P, Ferrer A, Domingo C, Mariscal D, et al: Lower respiratory tract infections following cardiac arrest and cardiopulmonary resuscitation. Clin Infect Dis 1995; 21: 310-4.

11) Perbet S, Mongardon N, Dumas F, Bruel C, Lemiale V, Mourvillier B, et al: Early-onset pneumonia after cardiac arrest: characteristics, risk factors and influence on prognosis. Am J Respir Crit Care Med 2011; 184: 1048-54. 
12) Acquarolo A, Urli T, Perone G, Giannotti C, Candiani A, Latronico N: Antibiotic prophylaxis of early onset pneumonia in critically ill comatose patients. A randomized study. Intensive Care Med 2005; 31: 510-6.

13) Gagnon DJ, Nielsen N, Fraser GL, Riker RR, Dziodzio J, Sunde K, et al: Prophylactic antibiotics are associated with a lower incidence of pneumonia in cardiac arrest survivors treated with targeted temperature management. Resuscitation 2015; 92: 154-9.

14) Kim SJ, Lee JK, Kim DK, Shin JH, Hong KJ, Heo EY: Effect of antibiotic prophylaxis on early-onset pneumonia in cardiac arrest patients treated with therapeutic hypothermia. Korean J Crit Care Med 2016; 31: 17-24. 